\title{
Altitude and Heat Training in Preparation for Competitions in the Heat: A Case Study
}

\author{
Amelia J. Carr, Philo U. Saunders, Laura A. Garvican-Lewis, and Brent S. Vallance
}

\begin{abstract}
Purpose: To quantify, for an elite-level racewalker, altitude training, heat acclimation and acclimatization, physiological data, and race performance from January 2007 to August 2008. Methods: The participant performed 7 blocks of altitude training: 2 "live high:train high" blocks at $1380 \mathrm{~m}$ (total = 22 d) and 5 simulated "live high:train low" blocks at $3000 \mathrm{~m} / 600 \mathrm{~m}$ (total = $98 \mathrm{~d}$ ). Prior to the 2007 World Championships and the 2008 Olympic Games, 2 heat-acclimation blocks of $\sim 6$ weeks were performed (1 session/week), with 2 weeks of heat acclimatization completed immediately prior to each $20-\mathrm{km}$ event. Results: During the observation period, physiological testing included maximal oxygen uptake $\left(\mathrm{VO}_{2} \mathrm{max}, \mathrm{mL} \cdot \mathrm{kg}^{-1} \cdot \mathrm{min}^{-1}\right)$, walking speed $\left(\mathrm{km} \cdot \mathrm{h}^{-1}\right)$ at $4 \mathrm{mmol} \cdot \mathrm{L}^{-1}$ blood lactate concentration $\left[\mathrm{La}^{-}\right]$, body mass $(\mathrm{kg})$, and hemoglobin mass $(\mathrm{g})$, and $12 \times 20-\mathrm{km} \mathrm{races} \mathrm{and} 2 \times 50-\mathrm{km}$ races were performed. The highest $\mathrm{VO}_{2} \max$ was $67.0 \mathrm{~mL} \cdot \mathrm{kg}^{-1} \cdot \mathrm{min}^{-1}$ (August 2007), which improved $3.1 \%$ from the first measurement $\left(64.9 \mathrm{~mL} \cdot \mathrm{kg}^{-1} \cdot \mathrm{min}^{-1}\right.$, June 2007). The highest percentage change in any physiological variable was $7.1 \%$, for $4 \mathrm{mmol} \cdot \mathrm{L}^{-1}\left[\mathrm{La}^{-}\right]$walking speed, improving from 14.1 (June 2007) to $15.1 \mathrm{~km} \cdot \mathrm{h}^{-1}$ (August 2007). Personal-best times for $20 \mathrm{~km}$ improved from (hh:mm:ss) 1:21:36 to 1:19:41 (2.4\%) and from 3:55:08 to 3:39:27 (7.1\%) in the 50-km event. The participant won Olympic bronze and silver medals in the $20-$ and $50-\mathrm{km}$, respectively. Conclusions: Elite racewalkers who regularly perform altitude training may benefit from periodized heat acclimation and acclimatization prior to major international competitions in the heat.
\end{abstract}

Keywords: hypoxic training, heat acclimation, elite athletes, periodization

For many endurance athletes, altitude training is a key component of their preparation for major competitions. ${ }^{1}$ According to the classical or live high:train high (LHTH) altitude-training model, athletes travel to venues of increased elevation to live and train for 2 to 4 weeks, in preparation for competitions held at either altitude or sea level. ${ }^{2}$ Live high:train low (LHTL) has also been used extensively, either by traveling to lower elevations to $\operatorname{train}^{3}$ or by utilizing simulated altitude environments (altitude houses or tents) and training at sea level. ${ }^{1}$ The effects of altitude training on elite athletes' performance, particularly during major competitions, have not been conclusively determined, ${ }^{4,5}$ but based on the existing literature, potential benefits include improved hemoglobin mass $\left(\mathrm{Hb}_{\text {mass }}\right)$, maximal oxygen uptake $\left(\mathrm{VO}_{2} \mathrm{max}\right),{ }^{6}$ submaximal exercise economy, ${ }^{7}$ and performance. ${ }^{2}$

Prior to competing in hot environments, athletes' preparation strategies may include, depending on their competition schedule and available facilities, heat acclimatization (living and training in a natural similar environment to the competition $)^{8}$ or acclimation (repeated heat exposures within a heat chamber/hot room, hot water immersion, or sauna bathing). ${ }^{1,9}$ Such strategies may induce adaptations including increased plasma volume, increased sweat rate, decreased core temperature, and reduced submaximal heart rate. ${ }^{8}$ However, optimal methods of preparation may be unclear to athletes who wish to use altitude training for improved competition performance, since altitude training locations can be cooler ${ }^{10}$ and

Carr is with the Centre for Sport Research, Deakin University, Burwood, VIC, Australia. Saunders and Garvican-Lewis are with Performance Services, Australian Inst of Sport, Bruce, ACT, Australia. Garvican-Lewis is also with the Mary MacKillop Inst for Health Research, Australian Catholic University, Melbourne, VIC, Australia. Vallance is with Physical Preparation, Maribyrnong Sports Academy, Maribyrnong, VIC, Australia, and Athletics Australia, Albert Park, VIC, Australia. Carr (amelia.carr@deakin.edu.au) is corresponding author. could inadvertently be deleterious for performance. ${ }^{11}$ The addition of heat acclimation/acclimatization within a periodized program that includes altitude training could thus potentially offer the "best of both worlds," but to our knowledge, has yet to be documented in a real-world competition context in elite endurance athletes.

The aim of this case study was to investigate, over a 20-month period, the following in an elite racewalker: (1) training data, altitude training interventions, and heat acclimation/acclimatization prior to competing in hot climates; (2) associated physiological data; and (3) 20- and 50-km race performance.

\section{Methods}

\section{Participant}

A male racewalker was observed over 20 months (January 1, 2007 to August 30, 2008). At the start of the data collection period, the participant's age was 23 years, $\mathrm{VO}_{2}$ max was $64.9 \mathrm{~mL} \cdot \mathrm{kg}^{-1} \cdot \mathrm{min}^{-1}$, and body mass was $58.9 \mathrm{~kg}$. The athlete had been in a full-time training environment at the Australian Institute of Sport (AIS, Canberra, ACT, Australia) for $\sim 3$ years. The experimental procedures were approved by the AIS Ethics Committee, and the athlete and his coach provided their approval for retrospective analysis.

\section{Procedures}

During the observation period, the athlete and coach were preparing for the World Championships (August 2007, Osaka, Japan) and the Olympic Games (August 2008, Beijing, China). Both major international championships were held in hot climates and, therefore, heat acclimation/acclimatization was incorporated into the training program. Training was performed according to a coachprescribed periodized plan. The training week typically included 
8 racewalking sessions ( 2 speed and 6 continuous), 3 running sessions, and cross-training sessions as required (eg, swimming sessions, in the event of injury). In September to October 2007, 2 resistance training sessions per week were added to the weekly program. Mean weekly training volume (in $\mathrm{km}$ ) performed in each month was recorded (Figure 1).

Seven altitude training blocks were performed: 2 blocks of LHTH (1380 m, Thredbo, Australia) and 5 blocks using simulated LHTL (3000 m for $14 \mathrm{~h} \cdot \mathrm{d}^{-1}: 600 \mathrm{~m}$ ) in the AIS Altitude House (Canberra, Australia). Weekly training volume $(\mathrm{km})$ and intensity (walking/running speed [min. $\mathrm{km}^{-1}$ ] and walking/running distance $\left.\left[\mathrm{km}>4 \mathrm{mmol} \cdot \mathrm{L}^{-1}\right]\right)$ performed before, during, and after heat and LHTL training blocks were recorded (Tables 1 and 2). Prior to departure for the Osaka World Championships, the athlete completed a 35-day LHTL block and 6-day post-LHTL recovery period. Concurrently, 1 heat acclimation session was completed per week, consistent with published recommendations for inducing heat adaptations in athletes, especially when combined with heat acclimatization performed immediately prior to major competitions, ${ }^{1,9}$ and therefore, 6 sessions in total were implemented prior to the 14-day prerace heat acclimatization period (Kochi, Japan). Details of training sessions and environmental conditions are provided in Table 1. Prior to the Beijing Olympic Games, a 21-day LHTL block and 7day recovery period, and a final 14-day LHTL period were implemented, concurrent with heat acclimation training (1 racewalking session per week), which commenced 38 days prior to departure from Australia (6 sessions in total). Heat acclimatization was performed (Kochi, Japan and Beijing, China) for the 15 days prior to the $20-\mathrm{km}$ event, as well as the subsequent 6 days prior to the 50-km event (Table 2).

Physiological testing was performed on 4 occasions. An incremental treadmill test was conducted on a custom-built treadmill (AIS, Canberra, Australia), according to methods described previously $^{12}$ (typical error of measurement of the system used, when using a similar test protocol, was $2.4 \%) .{ }^{7}$ Body mass (kg; A\&D Weighing, Adelaide, Australia), blood lactate concentration ( $\mathrm{mmol} \cdot \mathrm{L}^{-1}$; Lactate Pro, Arkray, Kyoto, Japan), heart rate (beats. $\mathrm{min}^{-1}$; Polar Electro Oy, Kempele, Finland), and oxygen consumption $\left(\mathrm{mL} \cdot \mathrm{kg}^{-1} \cdot \mathrm{min}^{-1}\right)$ using a custom-designed and built open-circuit indirect calorimetric system and associated software (AIS, Canberra, Australia) were measured on each occasion. $\mathrm{Hb}_{\text {mass }}$ was quantified on 18 occasions via carbon monoxide rebreathing as previously described. ${ }^{12}$ (Typical error of measurement for the procedure was $1.4 \%$. $)^{13}$

The participant performed 14 sanctioned races over Olympic distances $(12 \times 20$ - and $2 \times 50-\mathrm{km}$ races $)$.

\section{Statistical Analyses}

Data are reported using descriptive statistics. Changes observed within the data-collection period are reported as the percentage change compared with the first recorded measurement.

\section{Results}

\section{Altitude and Heat Training and Physiological Data}

Details of LHTL altitude training and heat acclimation/acclimatization are described in Table 1 . The highest recorded $\mathrm{VO}_{2} \mathrm{max}$ result was $67.0 \mathrm{~mL} \cdot \mathrm{kg}^{-1} \cdot \mathrm{min}^{-1}$ (August 2007), a 3.2\% improvement from the first measurement recorded during the data collection period $\left(64.9 \mathrm{~mL} \cdot \mathrm{kg}^{-1} \cdot \mathrm{min}^{-1}\right.$, June 2007). There was a $7.1 \%$ change in $4-\mathrm{mmol} \cdot \mathrm{L}^{-1}$ blood lactate concentration $\left[\mathrm{La}^{-}\right]$walking

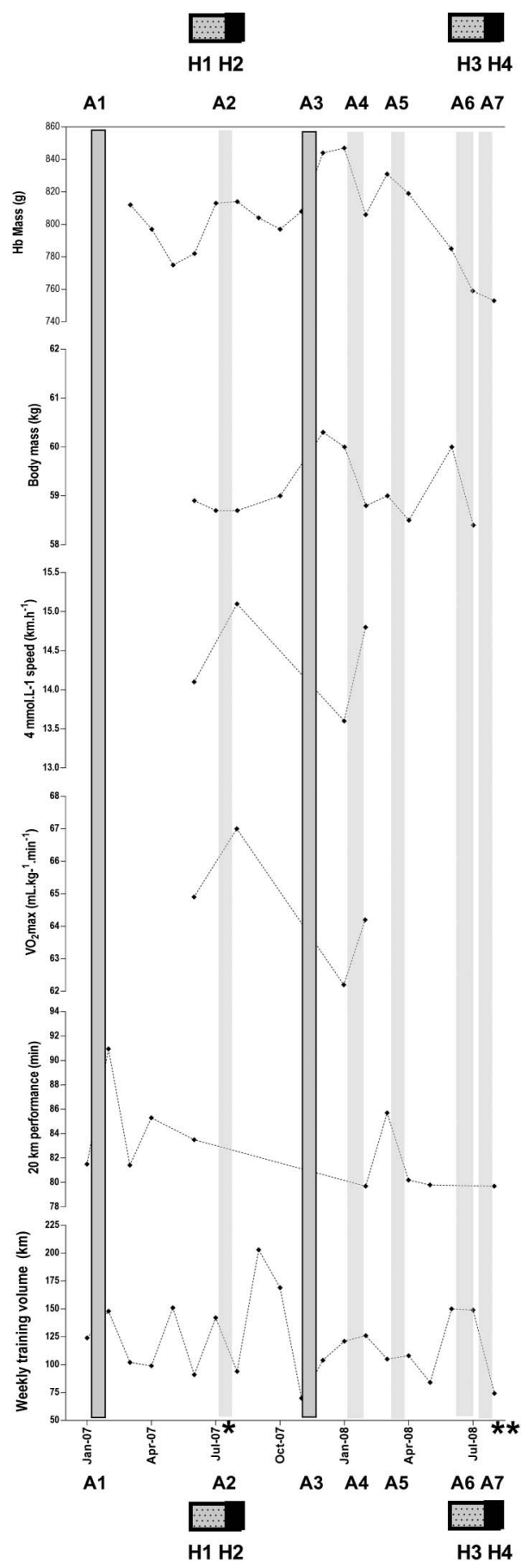

Figure 1 - Physiological data and training summary for the 20 months from January 2007 to August 2008. (A) $\mathrm{Hb}_{\text {mass }}$ (g), (B) body mass $(\mathrm{kg})$, (C) treadmill speed $\left(\mathrm{km} \cdot \mathrm{h}^{-1}\right)$ at $4 \mathrm{mmol} \cdot \mathrm{L}^{-1}$ blood $\left[\mathrm{La}^{-}\right]$, (D) $\mathrm{VO}_{2} \max \left(\mathrm{mL} \cdot \mathrm{kg}^{-1} \cdot \mathrm{min}^{-1}\right)$, (E) $20-\mathrm{km}$ performance time (min), and (F) mean weekly training volume $(\mathrm{km})$. Gray bars denote altitude-training blocks as follows: A1, LHTH 1380 m for 14 days; A2, LHTL 3000 m, 25 of 35 days; A3, LHTH 1380 m, 8 days due to hamstring injury; A4, LHTL 3000 m, 21 days; A5, LHTL 3000 m, 17 days; A6, LHTL, 3000 m, 21 days; and A7, LHTL $3000 \mathrm{~m}, 14$ days. Heat training as indicated by checked boxes: H1, 6-week heat acclimation of 1 session/week; H2, 14-day acclimatization prior to competition; $\mathrm{H} 3$, specific heat acclimation for 6 weeks $(1 \times$ per week); and H4, 15-day acclimatization prior to competition. $\mathrm{Hb}_{\text {mass }}$ indicates hemoglobin mass; $\mathrm{LHTH}$, live high:train high; LHTL, live high:train low. *World Championships, Osaka 2007. **Olympic Games, Beijing 2008. 
Table 1 Details of Total Training Duration, Volume, and Mean Intensity; LHTL Altitude Training, Heat-Acclimation, and Heat-Acclimatization Training (June 2007 to February 2008)

\begin{tabular}{|c|c|c|c|c|c|c|c|}
\hline Training intervention & $\begin{array}{l}\text { Pre- } \\
\text { LHTL }\end{array}$ & LHTL $^{a}$ & Post-LHTLa & $\begin{array}{c}\text { Heat } \\
\text { acclimatization }^{\mathbf{b}}\end{array}$ & $\begin{array}{l}\text { Pre- } \\
\text { LHTL }\end{array}$ & LHTL & $\begin{array}{l}\text { Post- } \\
\text { LHTL }\end{array}$ \\
\hline Location & Canberra & Canberra & Canberra & Kochi/Osaka & Canberra & Canberra & Canberra \\
\hline Date & Jun 07 & Jul 07 & Aug 07 & Aug 07 & Dec 07 & Jan 08 & $\mathrm{Jan} / \mathrm{Feb} 08$ \\
\hline Elevation, $\mathrm{m}$ & 600 & $3000 / 600$ & 600 & 10 & 600 & $3000 / 600$ & 600 \\
\hline Duration, $\mathrm{d}$ & 21 & 25 (of 35$)$ & 6 & 15 & 21 & 21 & 21 \\
\hline Walking volume, $\mathrm{km}$ & 193 & 537 & 92 & 188 & 135 & 303 & 285 \\
\hline Walking duration, $\mathrm{h}$ & $15: 54: 09$ & $42: 22: 29.0$ & $7: 22: 53.0$ & $15: 46: 34$ & 11:04:59.0 & $25: 27: 30.0$ & $23: 22: 29.0$ \\
\hline Walking pace, $\min \cdot \mathrm{km}^{-1}$ & 04:56.6 & $0: 04: 44.3$ & $04: 48.8$ & 0:05:02.1 & $0: 04: 55.5$ & 0:05:02.5 & 0:04:54.9 \\
\hline Running volume, $\mathrm{km}$ & 40 & 171 & 30 & 110 & 46 & 100 & 53 \\
\hline Training $\geq 4 \mathrm{mmol} \cdot \mathrm{L}^{-1}, \mathrm{~km}$ & 28 & 110 & 24 & 37 & 28 & 40 & 52 \\
\hline Training $\geq 4 \mathrm{mmol} \cdot \mathrm{L}^{-1}, \%$ & 12.0 & 15.5 & 19.7 & 12.4 & 15.5 & 9.9 & 15.4 \\
\hline Temperature $(7 \mathrm{AM}),{ }^{\circ} \mathrm{C}$ & 3.9 & 2.0 & 7.0 & 26.3 & 14.5 & 16.6 & 14.6 \\
\hline Temperature $(8 \mathrm{AM}),{ }^{\circ} \mathrm{C}$ & 4.5 & 2.8 & 7.5 & 28.0 & 16.1 & 17.8 & 16.1 \\
\hline \multicolumn{8}{|l|}{ Heat exposure } \\
\hline Frequency, sessions per week & Nil & 1 & 1 & $9-11$ & Nil & Nil & Nil \\
\hline Duration, min & NA & $60-70$ & $60-70$ & $78 \mathrm{~min} \cdot \mathrm{d}^{-1}$ & NA & NA & NA \\
\hline Intensity (low/moderate/high) & NA & Low & Low & Moderate-high & NA & NA & NA \\
\hline Conditions & NA & $30^{\circ} \mathrm{C} ; 60 \% \mathrm{RH}$ & $30^{\circ} \mathrm{C} ; 60 \% \mathrm{RH}$ & $29^{\circ} \mathrm{C} ; 76 \% \mathrm{RH}$ & NA & NA & NA \\
\hline
\end{tabular}

Abbreviations: LHTL, live high:train low; RH, relative humidity. Note: Temperature (in ${ }^{\circ} \mathrm{C}$ ) is provided at times corresponding to the start of outdoor training sessions (either 7 or $8 \mathrm{AM}$ ).

${ }^{\mathrm{a}}$ Time periods where heat-acclimation/acclimatization training was performed. ${ }^{\mathrm{b}}$ Heat-acclimatization period included the Osaka 2007 World Championships, where the athlete competed in the $20-\mathrm{km}$ event.

speed $\left(\mathrm{km} \cdot \mathrm{h}^{-1}\right)$ over the same time period. The highest $\mathrm{Hb}_{\text {mass }}$ result was $847 \mathrm{~g}$ (January 2008), with a $4.1 \%$ increase from the first recorded measurement ( $812 \mathrm{~g}$, June 2007). The lowest body mass was $57.6 \mathrm{~kg}$ (January 2008), a 2.3\% reduction from the initial measurement (58.9 kg, June 2007; Figure 1).

\section{Performance}

Compared with the baseline personal best (pb) 20-km performance upon commencement of the data collection period $(1: 21: 36$, La Coruña, Spain, May $2006 ; 19^{\circ} \mathrm{C}$ and $72 \%$ relative humidity $[\mathrm{RH}]$ ), there was a $2.4 \%$ improvement, with a pb performance of 1:19:41 (Melbourne, Australia, February $2008,13.5^{\circ} \mathrm{C}, 77 \% \mathrm{RH}$ ). The best performance in a major international competition for $20 \mathrm{~km}$ was 1:19:42, which earned a bronze medal at the 2008 Olympic Games, where the weather conditions at the start of the race were $29^{\circ} \mathrm{C}$ and $45 \% \mathrm{RH}$. The participant also competed in the $20-\mathrm{km}$ event at the 2007 World Championships (weather conditions at the start of the race were $32^{\circ} \mathrm{C}$ and $51 \% \mathrm{RH}$ ), but did not finish due to disqualification. There was a $7.1 \%$ improvement in $50-\mathrm{km}$ performance, from a pb of 3:55:08, (Geelong, Australia, December 2006; $11.1^{\circ} \mathrm{C}$ and $77 \% \mathrm{RH}$ ) to $3: 39: 27$ at the Olympic Games (Figure 1), where the participant won a silver medal. The environmental conditions at the start of the $50-\mathrm{km}$ event were $19^{\circ} \mathrm{C}$ and $97 \% \mathrm{RH}$. During the 50-km event, (at $10 \mathrm{AM}$ ) the environmental conditions were $29^{\circ} \mathrm{C}$ and $55 \% \mathrm{RH}$.

\section{Discussion}

This case study aimed to quantify altitude training (LHTH and LHTL) and heat acclimation/acclimatization training strategies prior to major international races held in hot climates, by an elite racewalker.
The participant's fastest 20-km time (1:19:41) was performed in February 2008, at the National Championships. The race was performed 30 days after 21 days of LHTL, and therefore, consistent with previous findings that postaltitude performance benefits can be supported by a concurrent increase in training load ${ }^{14}$ and may be maintained for up to 4 weeks. ${ }^{15}$ The hypoxic dose $(\sim 1008 \mathrm{~km} \cdot \mathrm{h})$ was also within the range typically required for performance improvement. ${ }^{16}$ Postaltitude increases in $\mathrm{Hb}_{\text {mass }}$ can contribute to improvements in performance, ${ }^{2}$ and indeed, the $\mathrm{Hb}_{\text {mass }}$ measured upon conclusion of the 21 days of LHTL was the highest observed during the data collection period $(847 \mathrm{~g})$. Nonhematological mechanisms can also contribute toward performance improvement, ${ }^{1}$ and there was an $8.8 \%$ improvement in $4 \mathrm{mmol} \cdot \mathrm{L}^{-1}$ $\left[\mathrm{La}^{-}\right]$speed between pre-LHTL and post-LHTL measures, compared with a $3.2 \%$ improvement in $\mathrm{VO}_{2}$ max at the same time point. The observation supports previous evidence that racewalking performance is highly correlated with submaximal exercise economy. ${ }^{17}$

Heat acclimation/acclimatization training was implemented with the aim of reducing the performance decrement that can occur when nonacclimated athletes are competing in hot climates, ${ }^{8,9,11}$ as part of a periodized program that included regular altitude training blocks. Simulated LHTL was implemented with the aim of increasing hypoxic dose and maintaining training intensity $^{3}$ to increase the potential for performance benefit. ${ }^{1}$ The hot climates expected for both the World Championships and Olympic Games (with temperatures at the start of the 20-km events of $32^{\circ} \mathrm{C}$ and $29^{\circ} \mathrm{C}$, respectively) presented challenging environmental conditions, especially compared with the cool conditions $\left(<7^{\circ} \mathrm{C}\right)$ recorded during morning training sessions in Canberra prior to the participants' departure to these major events. While unfortunately, the athlete was disqualified at the World 
Table 2 Details of Total Training Duration (h), Volume (km), and Mean Intensity (min. $\mathrm{km}^{-1}$ ); LHTL Altitude Training, Heat-Acclimation, and Heat-Acclimatization Training (February 2008 to August 2008)

\begin{tabular}{|c|c|c|c|c|c|c|c|c|}
\hline Training intervention & $\begin{array}{l}\text { Pre- } \\
\text { LHTL }\end{array}$ & LHTL & Post-LHTL & $\begin{array}{l}\text { Pre- } \\
\text { LHTL }\end{array}$ & LHTL $^{a}$ & $\begin{array}{l}\text { Post-LHTL/ } \\
\text { Pre-LHTL }\end{array}$ & LHTL $^{a}$ & $\begin{array}{l}\text { Post-LHTL/heat } \\
\text { acclimatization }^{\mathrm{b}}\end{array}$ \\
\hline Location & Canberra & Canberra & $\begin{array}{l}\text { Canberra/ } \\
\text { Beijing/ } \\
\text { London }\end{array}$ & Canberra & Canberra & Canberra & Canberra & Kochi/Beijing \\
\hline Date & $\begin{array}{c}\mathrm{Feb} / \mathrm{Mar} \\
08\end{array}$ & $\begin{array}{l}\text { Mar/Apr } \\
\quad 08\end{array}$ & Apr 08 & May 08 & Jun 08 & Jul 08 & Jul 08 & Aug 08 \\
\hline Elevation, m & 600 & $3000 / 600$ & $600 / 44 / 11$ & 600 & $3000 / 600$ & 600 & $3000 / 600$ & $5 / 44$ \\
\hline Duration, $\mathrm{d}$ & 21 & 17 & 21 & 21 & 21 & 7 & 14 & 21 \\
\hline Walking volume, $\mathrm{km}$ & 170 & 242 & 240 & 290 & 421 & 83 & 289 & 345 \\
\hline Walking duration, $\mathrm{h}$ & $14: 18: 06.0$ & $19: 30: 04.0$ & $19: 34: 29.0$ & $23: 36: 22.0$ & $34: 08: 45.0$ & 7:03:19.0 & $23: 25: 15.0$ & $27: 16: 28.0$ \\
\hline Walking pace, $\min \cdot \mathrm{km}^{-1}$ & $05: 03.6$ & $04: 49.7$ & 04:53.9 & $04: 52.6$ & $04: 51.7$ & 05:04.9 & 04:51.9 & $04: 44.9$ \\
\hline Running volume, $\mathrm{km}$ & 40 & 89 & 62 & 115 & 91 & 30 & 60 & 122 \\
\hline Training $\geq 4 \mathrm{mmol} \cdot \mathrm{L}^{-1}, \mathrm{~km}$ & 28 & 40 & 52 & 75 & 70 & 4 & 38 & 105 \\
\hline Training $\geq 4 \mathrm{mmol} \cdot \mathrm{L}^{-1}, \%$ & 13.4 & 12.1 & 17.2 & 18.5 & 13.7 & 3.5 & 10.9 & 22.5 \\
\hline $\begin{array}{l}\text { Temperature } \\
(7 \mathrm{AM}),{ }^{\circ} \mathrm{C}\end{array}$ & 11.5 & 10.3 & 7.1 & 3.6 & 4.6 & 0.9 & -0.3 & 26.6 \\
\hline $\begin{array}{l}\text { Temperature } \\
(8 \mathrm{AM}),{ }^{\circ} \mathrm{C}\end{array}$ & 13.0 & 10.8 & 9.2 & 2.7 & 2.2 & 4.5 & 4.8 & 28.1 \\
\hline \multicolumn{9}{|l|}{ Heat acclimation } \\
\hline $\begin{array}{l}\text { Frequency, } \\
\text { per week }\end{array}$ & Nil & Nil & Nil & Nil & 1 & 1 & 1 & $10-11$ \\
\hline Duration, min & NA & NA & NA & NA & $60-70$ & $60-70$ & 80 & $80 \mathrm{~min} \cdot \mathrm{d}^{-1}$ \\
\hline $\begin{array}{l}\text { Intensity (low/moderate/ } \\
\text { high) }\end{array}$ & NA & NA & NA & NA & Low & Low & High & Moderate-high \\
\hline Conditions & NA & NA & NA & NA & $\begin{array}{l}33^{\circ} \mathrm{C} \\
60 \% \mathrm{RH}\end{array}$ & $\begin{array}{l}33^{\circ} \mathrm{C} \\
60 \% \mathrm{RH}\end{array}$ & $\begin{array}{l}33^{\circ} \mathrm{C} \\
60 \% \mathrm{RH}\end{array}$ & $29^{\circ} \mathrm{C} ; 76 \% \mathrm{RH}$ \\
\hline
\end{tabular}

Abbreviations: LHTL, live high:train low; RH, relative humidity. Note: Temperature (in ${ }^{\circ} \mathrm{C}$ ) is provided at times corresponding to the start of outdoor training sessions (either 7 or $8 \mathrm{AM}$ ).

${ }^{\mathrm{a}}$ Time periods where heat-acclimation/acclimatization training was performed. ${ }^{\mathrm{b}}$ Heat-acclimatization period included the 2008 Beijing Olympic Games, where the athlete competed in the 20 - and $50-\mathrm{km}$ events.

Championships and, therefore, the performance effect cannot be quantified, at the Olympic Games, he earned a 50-km silver medal and $\mathrm{pb}$ time and performed within 1 second of his $20-\mathrm{km} \mathrm{pb}$, winning a bronze medal. In the current case study, the observed postaltitude training $\mathrm{VO}_{2}$ max and $\mathrm{Hb}_{\text {mass }}$ increases may have contributed to the athlete's medal-winning performances. ${ }^{6}$ The concurrent inclusion of heat acclimation and acclimatization in the athlete's periodized competition preparation ${ }^{11}$ and the potential for adaptations, including reduced core temperature, increased sweat rates, and improved cardiovascular stability, ${ }^{8}$ may have had some effect on the athlete's performance in both hot and temperate conditions. ${ }^{18}$

\section{Practical Applications}

When preparing for major international competitions in the heat, elite racewalkers' performance may benefit from LHTL within 4 weeks prior to racing, particularly when building upon previous altitude exposure. The addition of heat acclimation and acclimatization during the 8 weeks prior to major international competitions in the heat may induce heat adaptations and reduce the likelihood of performance decrement associated with acute heat stress.

\section{Conclusions}

We recommend that, for elite racewalkers who regularly perform altitude training, the addition of periodized heat acclimation and acclimatization may assist with preparation for competitions held in hot and humid conditions.

\section{Acknowledgments}

The authors would like to thank the participant for their involvement in this case study. During the observation period, the participant received support from the Australian Institute of Sport and Athletics Australia.

\section{References}

1. Saunders P, Garvican-Lewis L, Chapman R, Périard J. Special environments: altitude and heat. Int J Sport Nutr Exerc Metab. 2019;29(2):210-219. PubMed ID: 30676138 doi:10.1123/ijsnem. 2018-0256

2. Saunders P, Pyne D, Gore C. Endurance training at altitude. High Alt Med Biol. 2009;10(2):135-148. PubMed ID: 19519223 doi:10.1089/ ham.2008.1092 
3. Levine B, Stray-Gundersen J. "Living high-training low": effect of moderate-altitude acclimatization with low-altitude training on performance. J Appl Physiol. 1997;83(1):102-112. PubMed ID: 9216951 doi:10.1152/jappl.1997.83.1.102

4. Robach P, Lundby C. Is live high-train low altitude training relevant for elite athletes with already high total hemoglobin mass? Scand J Med Sci Sports. 2012;22:303-305. PubMed ID: 22612361 doi:10. 1111/j.1600-0838.2012.01457.x

5. Millet G, Chapman R, Girard O, Brocherie F. Is live high-train low altitude training relevant for elite athletes? Flawed analysis from inaccurate data. Br J Sports Med. 2019;53(15):923-925. PubMed ID: 29247024 doi:10.1136/bjsports-2017-098083

6. Saunders P, Garvican-Lewis L, Schmidt W, Gore C. Relationship between changes in haemoglobin mass and maximal oxygen uptake after hypoxic exposure. Br J Sports Med. 2013;47:i26-i30. PubMed ID: 24282203 doi:10.1136/bjsports-2013-092841

7. Saunders P, Telford R, Pyne D, et al. Improved running economy in elite runners after 20 days of simulated moderate-altitude exposure. $J$ Appl Physiol. 2004;96:931-937. PubMed ID: 14607850 doi:10.1152/ japplphysiol.00725.2003

8. Périard J, Racinais S, Sawka M. Adaptations and mechanisms of human heat acclimation: applications for competitive athletes and sports. Scand J Med Sci Sports. 2015;25(suppl 1):20-38. doi:10. 1111/sms. 12408

9. Racinais S, Casa D, Brocherie F, Ihsan M. Translating science into practice: the perspective of the Doha 2019 IAAF World Championships in the heat. Front Sports Act Living. 2019;1(39):1-8.

10. Schmidt M, Askew E, Roberts D, Prior R, Ensign W, Hesslink R. Oxidative stress in humans training in a cold, moderate altitude environment and their response to a phytochemical antioxidant supplement. Wilderness Environ Med. 2002;13:94-105. PubMed ID: 12092978 doi:10.1580/1080-6032(2002)0130094:osihti]2.0.co;2
11. Mujika I, Sharma A, Stellingwerff T. Contemporary periodization of altitude training for elite endurance athletes: a narrative review. Sports Med. 2019;49:1651-1669. PubMed ID: 31452130 doi:10.1007/ s40279-019-01165-y

12. Carr A, Saunders P, Vallance B, Garvican-Lewis L, Gore C. Increased hypoxic dose after training at low altitude with $9 \mathrm{~h}$ per night at 3000m normobaric hypoxia. J Sports Sci Med. 2015;14:776782. PubMed ID: 26664274

13. Garvican-Lewis L, Halliday I, Abbiss C, Saunders P, Gore C. Altitude exposure at $1800 \mathrm{~m}$ increases haemoglobin mass in distance runners. J Sports Sci Med. 2015;14:413-417. PubMed ID: 25983592

14. Sharma A, Saunders P, Garvican-Lewis L, et al. Training quantification and periodization during live high train high at $2100 \mathrm{~m}$ in elite runners: an observational cohort case study. J Sports Sci Med. 2018;17:607-616. PubMed ID: 30479529

15. McLean B, Buttifant D, Gore C, White K, Liess C, Kemp J. Physiological and performance responses to a preseason altitudetraining camp in elite team-sport athletes. Int J Sports Physiol Perform. 2013;8:391-399. PubMed ID: 23170749 doi:10.1123/ ijspp.8.4.391

16. Garvican-Lewis L, Sharpe K, Gore C. Time for a new metric for hypoxic dose? J Appl Physiol. 2016;121:352-355. PubMed ID: 26917695 doi:10.1152/japplphysiol.00579.2015

17. Hagberg J, Coyle E. Physiological determinants of endurance performance as studied in competitive racewalkers. Med Sci Sports Exerc. 1983;15(4):287-289. PubMed ID: 6621317 doi:10.1249/ 00005768-198315040-00006

18. Lorenzo S, Halliwill J, Sawka M, Minson C. Heat acclimation improves exercise performance. J Appl Physiol. 2010;109:11401147. PubMed ID: 20724560 doi:10.1152/japplphysiol.00495. 2010 